\title{
Thermochemical Analysis of Hypergolic Propellants Based on Triethylaluminum/Nitrous Oxide
}

\author{
Stephen M. Davis and Nadir Yilmaz \\ Department of Mechanical Engineering, New Mexico Institute of Mining and Technology, Socorro, NM 87801, USA \\ Correspondence should be addressed to Nadir Yilmaz; yilmaznadir@yahoo.com
}

Received 6 June 2014; Accepted 30 July 2014; Published 27 August 2014

Academic Editor: Linda L. Vahala

Copyright ( 2014 S. M. Davis and N. Yilmaz. This is an open access article distributed under the Creative Commons Attribution License, which permits unrestricted use, distribution, and reproduction in any medium, provided the original work is properly cited.

\begin{abstract}
The vacuum specific impulse, density vacuum specific impulse, and solid exhaust products were examined for several propellant formulations based on the pyrophoric material triethylaluminum (TEA) using CEA thermodynamics code. Evaluation of TEA neat and mixed with hydrocarbon fuels with LOX, $\mathrm{N}_{2} \mathrm{O}, \mathrm{N}_{2} \mathrm{O}_{4}$, liquefied air, and $\mathrm{HNO}_{3}$ were performed at stoichiometry. The vacuum specific impulse of neat TEA with $\mathrm{N}_{2} \mathrm{O}$ is comparable to that of nitric acid with the same, but the $\mathrm{N}_{2} \mathrm{O}$ formulation will produce slightly less solid products during combustion. Additionally, $\mathrm{N}_{2} \mathrm{O}$-TEA propellants have vacuum specific impulses and density vacuum specific impulses within $92.9 \%$ and $86.7 \%$ of traditional hydrazine propellant formulations under stoichiometric conditions.
\end{abstract}

\section{Introduction}

Nitrous oxide is a commonly used propellant in various applications ranging from aerosol cans to racing vehicles and novel rocket propellants. Because nitrous oxide may selfpressurize, there has been significant work to develop novel monopropellants using this oxidizer [1-6]. Additionally, the oxidation potential of nitrous oxide makes it an oxidizer of comparable strength to hydrogen peroxide $(1.766 \mathrm{~V}$ and $1.776 \mathrm{~V}$, resp. [7]), where hydrogen peroxide is known to ignite hypergolically with pyrophoric materials such as silane and triethylaluminum (TEA) $[8,9]$. Pyrophoric materials such as TEA therefore appear to be ideal first-pass candidates for nitrous oxide hypergolic fuels. The case for these chemicals is further strengthened by the use of TEA and $\mathrm{SiH}_{4}$ as supersonic combustion aids, since supersonic combustion requires highly flammable fuels [9]. Moreover, TEA reduces the ignition delay of hydrazine with nitrogen tetroxide [9] and ignites with air at temperatures as low as $-40^{\circ} \mathrm{C}[10]$.

However, the mass burning rate of TEA $\left(0.029 \mathrm{~kg} / \mathrm{m}^{2}-\mathrm{s}\right)$ is much slower than short chain hydrocarbon fuels such as hexane $\left(0.077 \mathrm{~kg} / \mathrm{m}^{2}-\mathrm{s}\right)$ and isopentane $\left(0.103 \mathrm{~kg} / \mathrm{m}^{2}-\mathrm{s}\right)[11]$. TEA diluted with a hydrocarbon fuel has mass burning rates comparable to the neat hydrocarbon, depending on mixing ratio [12]. Mixing in a hydrocarbon solvent also improves the safety of TEA by preventing its ignition with atmospheric oxygen $[12,13]$. For these reasons it is important to determine not only the performance such as specific impulse (Isp), density specific impulse ( $\rho$ Isp), and ignition delay of TEA with a given oxidizer, but also the effect a solvent has on the system. In the current work, Isp, $\rho$ Isp, and the amount of condensed species in the exhaust were examined. For simplicity, all specific impulse values used refer to the vacuum specific impulse, not the specific impulse at sea level.

\section{Method}

A thermochemical evaluation of TEA mixed with hydrocarbon solvents hexane, methanol, aniline, nitromethane, and nitropropane was performed with the oxidizers liquid oxygen (LOX), nitrogen tetroxide $\left(\mathrm{NTO}, \mathrm{N}_{2} \mathrm{O}_{4}\right)$, nitrous oxide $\left(\mathrm{N}_{2} \mathrm{O}\right)$, liquefied air, and nitric acid $\left(\mathrm{HNO}_{3}\right)$ using the NASA Lewis Code Chemical Equilibrium with Applications (CEA2) [14]. Table 1 shows the density and molecular weight of propellant components. The binary fuels were prepared with $0,10,20,25,50,75$, and $100 \%$ TEA by mass. Each reaction was simulated at stoichiometry with a given oxidizer as determined by the method outlined in Jain et al. [15] at 
TABLE 1: Density and molecular weight of propellant components.

\begin{tabular}{lccc}
\hline Name & MW & Specific gravity (water =1) & Ref. \\
\hline Nitrous oxide & 44.01 & $1.2228^{\mathrm{a}}$ & {$[17]$} \\
Nitrogen tetroxide/ $\mathrm{NO}_{2}$ & 92.01 & 1.443 & {$[7]$} \\
Liquid oxygen & 32 & $1.1905^{\mathrm{b}}$ & {$[7]$} \\
Nitric acid & 63.01 & 1.5129 & {$[7]$} \\
Hydrazine & 32.05 & 1.0036 & {$[7]$} \\
MMH & 46.07 & 0.875 & {$[7]$} \\
UDMH & 60.1 & 0.791 & {$[7]$} \\
Methanol & 32.04 & 0.7914 & {$[7]$} \\
TEA & 114.17 & 0.832 & {$[7]$} \\
Hexane & 86.18 & 0.6606 & {$[7]$} \\
Nitromethane & 61.04 & 1.1371 & {$[7]$} \\
1-Nitropropane & 89.09 & 0.9961 & {$[7]$} \\
Aniline & 93.13 & 1.0217 & {$[7]$} \\
Air & 28.84 & $0.959^{\mathrm{c}}$ & {$[7]$} \\
\hline
\end{tabular}

${ }^{\mathrm{a}} 1.013$ bars, $184.5 \mathrm{~K}^{\mathrm{b}} 1.013$ bars, $80 \mathrm{~K} ;{ }^{\mathrm{c}} 59.75 \mathrm{~K}$.

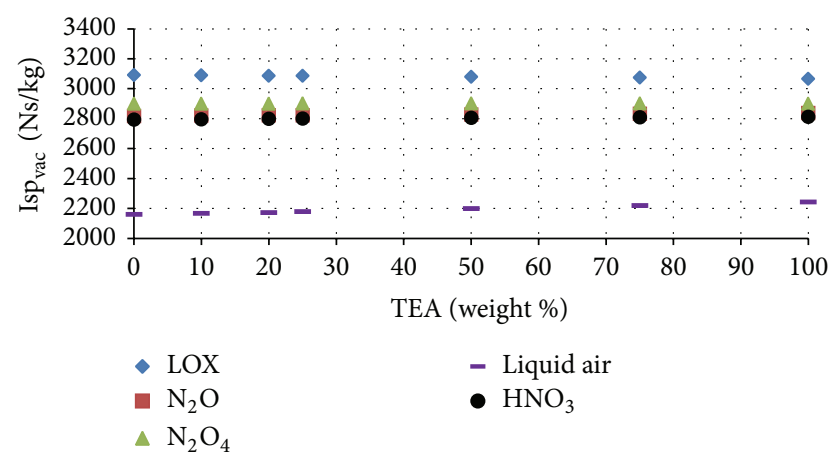

FIGURE 1: Isp $\mathrm{pac}_{\mathrm{vac}}$ of TEA-hexane fueled propellants.

a chamber pressure of $2.068 \mathrm{MPa}$. The initial temperature of each fuel component was set to $25^{\circ} \mathrm{C}$, with the exception of cryogenic components LOX $\left(-185^{\circ} \mathrm{C}\right)$ and liquid air $\left(-195^{\circ} \mathrm{C}\right)$. The heat of formation for TEA $\left(\mathrm{AlC}_{6} \mathrm{H}_{15}\right)$ and liquid air (79\% nitrogen, $21 \%$ oxygen) were manually added to CEA as $-187.3 \mathrm{~kJ} / \mathrm{mol}[16]$ and $0 \mathrm{~kJ} / \mathrm{mol}$. The chemistry was allowed to change through a simulated $1: 10$ expansion nozzle.

\section{Results and Discussion}

In terms of vacuum specific impulse ( Isp $_{\text {vac }}$ ) there is little difference between the performance of nitric acid and nitrous oxide. The average difference between $\mathrm{N}_{2} \mathrm{O}$ and $\mathrm{HNO}_{3}$ in terms of Isp $\mathrm{vac}_{\mathrm{vac}}$ was between $0.1 \%$ and $1.5 \%$, depending on the solvent. Depending on the concentration of TEA, the minimum Isp vac for the $\mathrm{N}_{2} \mathrm{O}$ and $\mathrm{HNO}_{3}$ formulations is $2794 \mathrm{Ns} / \mathrm{kg}$ for hexane, $2730 \mathrm{Ns} / \mathrm{kg}$ for methanol, $2728 \mathrm{Ns} / \mathrm{kg}$ for aniline, $2811 \mathrm{Ns} / \mathrm{kg}$ for nitromethane, and $2788 \mathrm{Ns} / \mathrm{kg}$ for nitropropane as seen in Figures 1, 2, 3, 4, and 5. The exception is methanol, where the minimum impulse was at $10 \%$ TEA when burned with $\mathrm{HNO}_{3}$ (Figure 2). The Isp vac for neat TEA with LOX, $\mathrm{N}_{2} \mathrm{O}, \mathrm{NTO}$, air, and $\mathrm{HNO}_{3}$ is $3066 \mathrm{Ns} / \mathrm{kg}$,

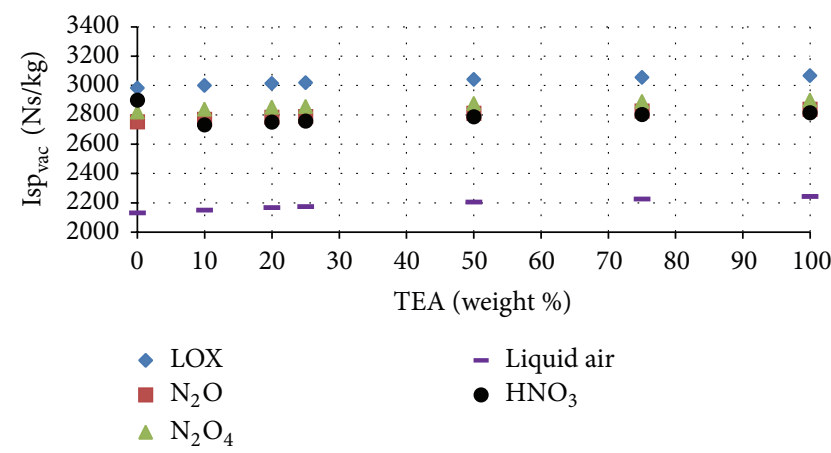

FIGURE 2: Isp ${ }_{\text {vac }}$ of TEA-methanol fueled propellants.

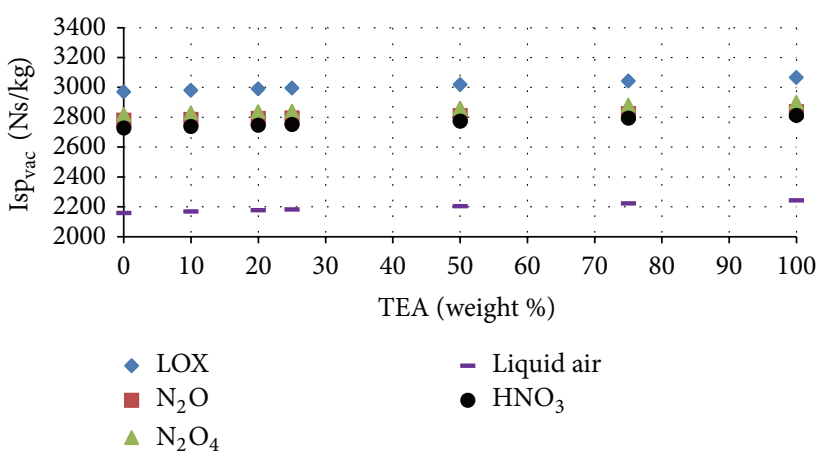

FIgURE 3: Isp $p_{\text {vac }}$ of TEA-aniline fueled propellants.

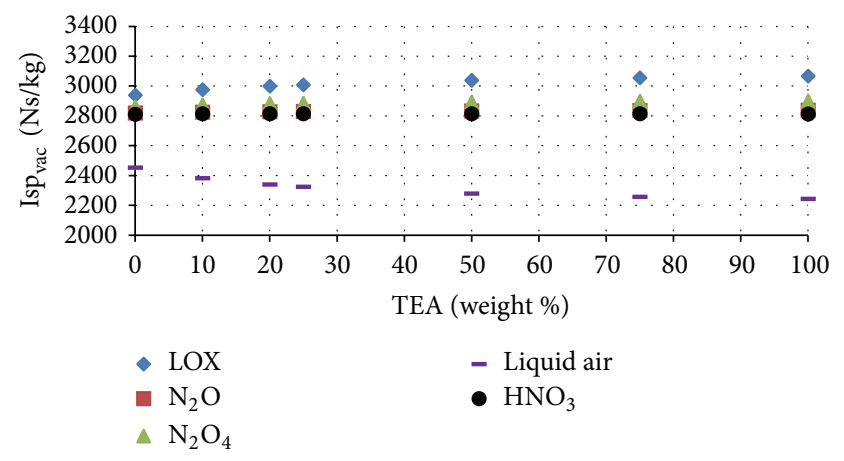

FIGURE 4: Isp $\mathrm{pac}_{\mathrm{vac}}$ of TEA-nitromethane fueled propellants.

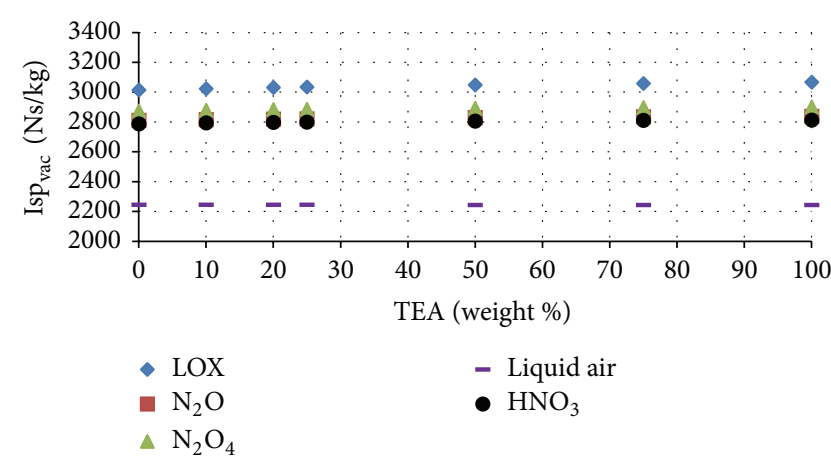

FIGURE 5: Isp ${ }_{\text {vac }}$ of TEA-1-nitropropane fueled propellants. 


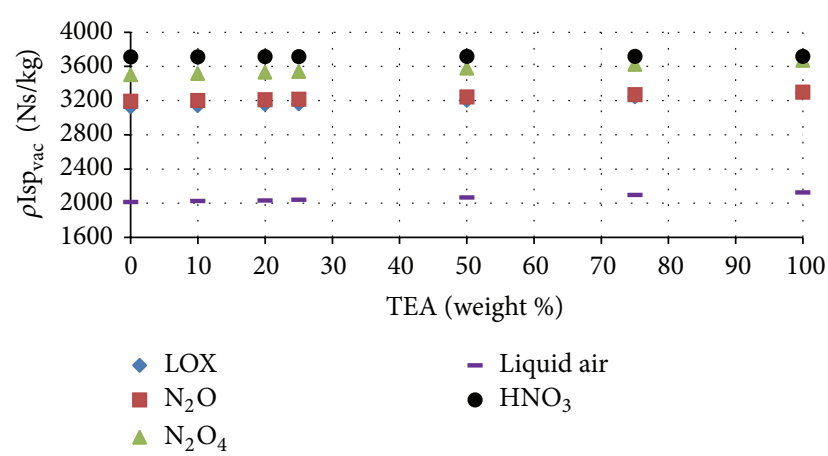

FIGURE 6: $\rho$ Isp $_{\text {vac }}$ of TEA-hexane fueled propellants.

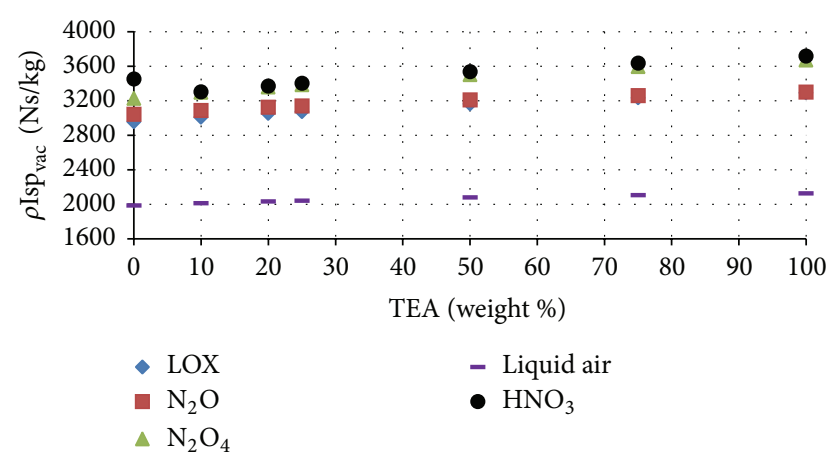

FIGURE 7: $\rho \mathrm{Isp}_{\mathrm{vac}}$ of TEA-MeOH fueled propellants.

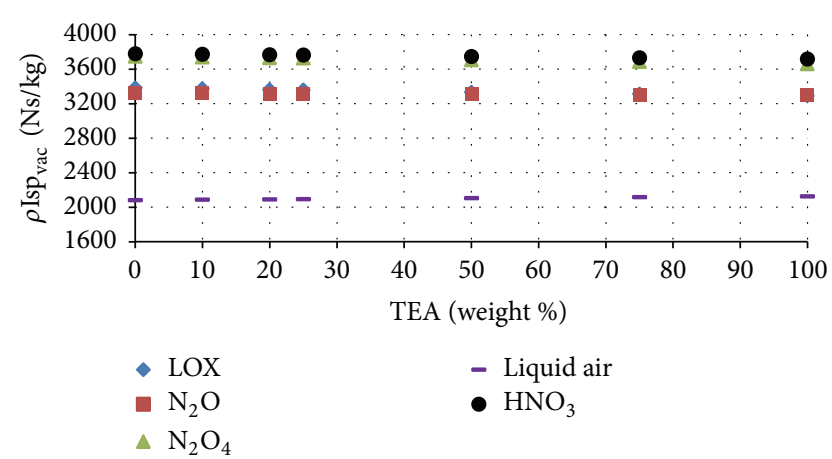

FIgURE 8: $\rho \mathrm{Isp}_{\mathrm{vac}}$ of TEA-aniline fueled propellants.

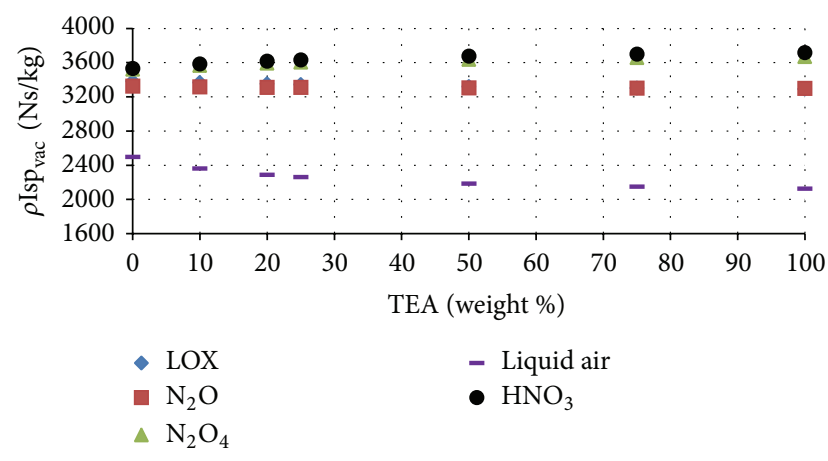

FIGURE 9: $\rho \mathrm{Isp}_{\mathrm{vac}}$ of TEA-nitromethane fueled propellants.

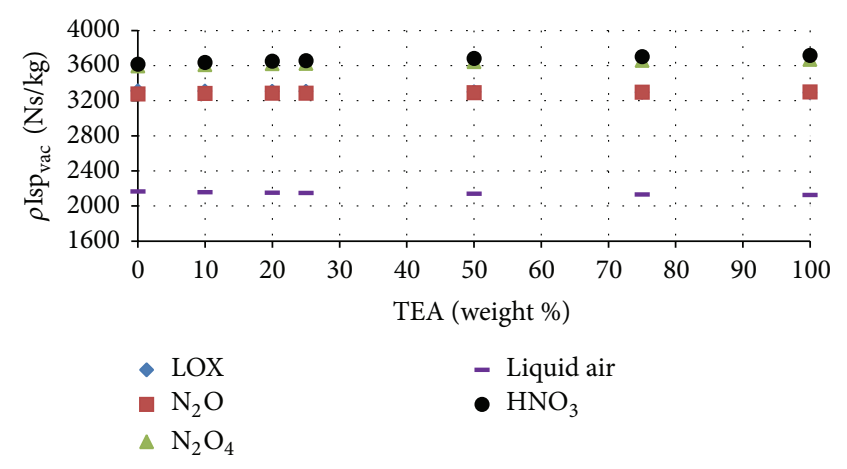

FIGURE 10: $\rho \mathrm{Isp}_{\mathrm{vac}}$ of TEA-1-nitropropane fueled propellants.

$2838 \mathrm{Ns} / \mathrm{kg}, 2901 \mathrm{Ns} / \mathrm{kg}, 2243 \mathrm{Ns} / \mathrm{kg}$, and $2813 \mathrm{Ns} / \mathrm{kg}$, respectively. LOX and $\mathrm{N}_{2} \mathrm{O}_{4}$ formulations were predicted to have an average $6.3-9 \%$ and $1.8-2.7 \%$ greater impulse, respectively, than $\mathrm{N}_{2} \mathrm{O}$ formulations, depending on the solvent and TEA concentration. The specific impulse of $\mathrm{N}_{2} \mathrm{O}$ was $21.7-28.9 \%$ greater than for the liquefied air series, depending on solvent.

In a rocket, it is important to consider not only the thrust a propellant may produce, but also how large of a storage tank the propellant requires; the lower the density of the formulation the greater the volume it occupies and therefore requires a more massive storage tank, increasing the total mass of the rocket. Therefore, it is necessary to evaluate the impulse weighted by the density of the propellant. In order to maintain units, the specific gravity of each propellant (with water equal to 1.0) was multiplied to the vacuum specific impulse. Figures $6,7,8,9$, and 10 show nearly equivalent $\rho \mathrm{Isp}_{\text {vac }}$ for the oxidizers LOX and $\mathrm{N}_{2} \mathrm{O}$, regardless of the secondary fuel. As seen in the figures, the impulses are between 3126 and $3299 \mathrm{Ns} / \mathrm{kg}$ for hexane, 3291 and $3382 \mathrm{Ns} / \mathrm{kg}$ for aniline, 3291 and $3383 \mathrm{Ns} / \mathrm{kg}$ for nitromethane, and 3277 and $3311 \mathrm{Ns} / \mathrm{kg}$ for nitropropane, depending on TEA concentration.

With the exception of aniline and methanol, the highest impulse for these formulations is for neat TEA and the least for neat fuel. Neat aniline had the highest $\rho$ Isp in its series with the lowest impulse with neat TEA. The minimum $\rho$ Isp for methanol was calculated for 10\% TEA, with neat TEA having the highest impulse. Density impulses for nitric acid with fuel were comparable to those of nitrogen tetroxide with fuel for all TEA formulation besides hexane, where the nitric acid had on average $4.1 \%$ higher density impulse than nitrogen tetroxide formulations. On average, nitric acid outperformed $\mathrm{N}_{2} \mathrm{O}$ formulations by $9.8-14.9 \%$ and nitrogen tetroxide outperforms $\mathrm{N}_{2} \mathrm{O}$ by $8.4-12.2 \%$. Nitrous oxide had density vacuum specific impulses $46-57.7 \%$ greater than for liquefied air propellants on average.

Generally, as with the Isp vac values, the effect of the secondary fuel on the $\rho \mathrm{Isp}_{\mathrm{vac}}$ is minimal, suggesting that dilution of TEA will not hamper thrust characteristics assuming hypergolic ignition is achieved. This in turn will permit a minimal TEA to be utilized. This feature ought to be advantageous given the burn rates discussed in [12] where TEA burns up to one-third the rate of a hydrocarbon. 
TABLE 2: Summary of Isp, $\rho$ Isp, and solid exhaust for neat TEA.

\begin{tabular}{lccc}
\hline Oxidizer & Isp & $\rho$ Isp & \% solid \\
\hline LOX & 3066 & 3291 & 11.3 \\
$\mathrm{~N}_{2} \mathrm{O}$ & 2838 & 3299 & 4.9 \\
$\mathrm{~N}_{2} \mathrm{O}_{4}$ & 2901 & 3670 & 8.5 \\
$\mathrm{Air}$ & 2243 & 2127 & 3.3 \\
$\mathrm{HNO}_{3}$ & 2813 & 3716 & 5.7 \\
\hline
\end{tabular}

In addition to the impulse calculations, the condensed exhaust species were examined. Because solid exhaust products tend to erode the rocket nozzle, it is desirable to minimize solid exhaust products. Obviously, a fuel containing no condensable species (i.e., no aluminum) will have no solids in the exhaust; therefore the solids fraction of neat TEA with each oxidizer at stoichiometry was calculated to isolate the effect of the oxidizer on the products formed. It was observed that $\mathrm{N}_{2} \mathrm{O}$ and air have the lowest fraction of solids loading in the exhaust as a result of the high oxidizerfuel ratios for these formulations. A majority of the solid exhaust products were in the form of $\mathrm{Al}_{2} \mathrm{O}_{3}$, with small amounts of $\mathrm{AlOH}$ and $\mathrm{Al}(\mathrm{OH})_{3}$. The highest solids fraction was calculated for LOX. Table 2 is a summary of the Isp, $\rho \mathrm{Isp}_{\mathrm{vac}}$, and solids fraction. Regardless of oxidizer selection, the solids fraction is expected to be below $12 \%$, which is significantly less than many solid rocket propellants which may contain $20 \%$ solid aluminum in the fuel. A blended fuel (TEA and hydrocarbon) would have even less solid product, depending on mixing ratio, and therefore would be expected to have retarded nozzle erosion compared to a solid rocket fuel and therefore higher combustion stability.

For comparison to conventionally used propellants based on hydrazine, the Isp $\mathrm{pac}_{\mathrm{vac}}$ and $\rho \mathrm{Isp}_{\mathrm{vac}}$ of hydrazine-oxidizer systems (neat hydrazine, monomethylhydrazine (MMH), unsymmetrical dimethylhydrazine (UDMH), and Aerozine 50) are shown in Figures 11 and 12, respectively. The highest Isp for the neat hydrazines is hydrazine-LOX at $3299 \mathrm{Ns} / \mathrm{kg}$. Once again, the lowest impulse is observed for liquid air. The highest $\rho$ Isp ${ }_{\text {vac }}$ is $3788 \mathrm{Ns} / \mathrm{kg}$ for hydrazine $\mathrm{N}_{2} \mathrm{O}_{4}$. With respect to only the hydrazines, $\mathrm{N}_{2} \mathrm{O}$ produces no less than $88 \%$ of the maximum calculated impulse and $86 \%$ of the maximum $\rho \mathrm{Isp}_{\mathrm{vac}}$. The worst performing $\mathrm{N}_{2} \mathrm{O}$ system in this investigation (neat methanol- $\mathrm{N}_{2} \mathrm{O}$ ) had an Isp vac within $83 \%$ and $\rho \mathrm{Isp}_{\mathrm{vac}}$ within $80 \%$ of the best performing hydrazine system. Neat TEA- $\mathrm{N}_{2} \mathrm{O}$ had an Isp vac within $92.9 \%$ of the hydrazine-LOX and $\rho \mathrm{Isp}_{\mathrm{vac}} 86.9 \%$ of the hydrazine-NTO formulations. In brief, TEA- $\mathrm{N}_{2} \mathrm{O}$ propellants are expected to produce comparable impulse values to hydrazine-based propellants.

\section{Conclusions}

A thermodynamic analysis of potential hypergolic propellants based on TEA and nitrous oxide was performed and compared to traditional oxidizers. It was shown that nitrous oxide is comparable to nitric acid in terms of specific impulse, and in terms of density specific impulse nitrous oxide is

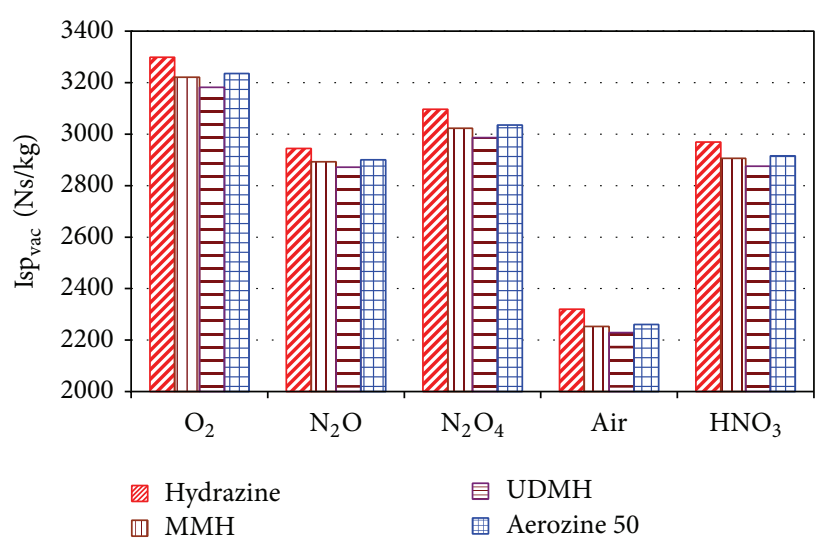

FIGURE 11: Isp $\mathrm{pac}_{\mathrm{vac}}$ of hydrazine-based propellants.

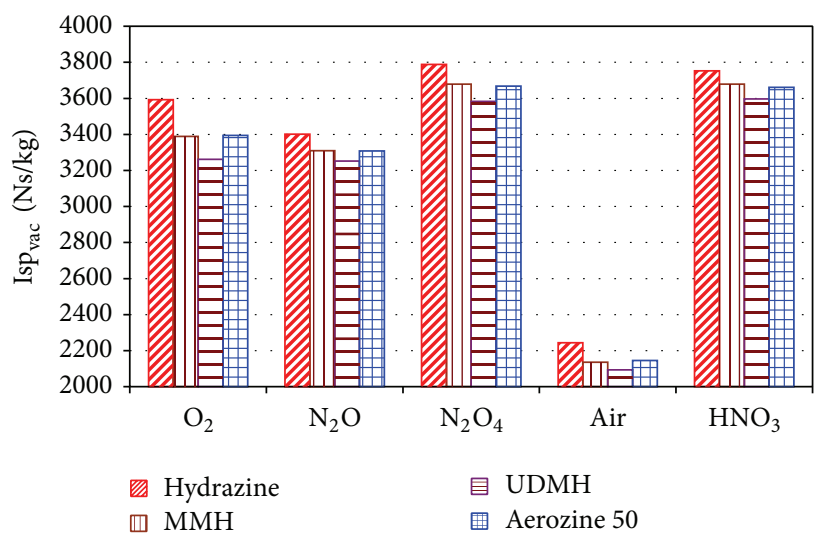

FIGURE 12: $\rho I_{\text {sp }}$ vac of hydrazine-based propellants.

comparable to LOX. However, the high oxidizer/fuel ratio for nitrous oxide helps to minimize the solids fraction of the exhaust, which is desirable. The effect of a secondary fuel such as hexane, $\mathrm{MeOH}$, aniline, nitromethane, and 1-nitropropane was also examined and was deemed minimal. Because the thrust characteristics of a TEA fuel blend are minimally affected by the addition of a hydrocarbon fuel, a minimal volume of TEA may be utilized assuming hypergolic ignition can be confirmed. Moreover, the neat TEA- $\mathrm{N}_{2} \mathrm{O}$ propellant produces vacuum specific impulses and density specific impulses $7.1 \%$ and $13.1 \%$ lower than traditional hydrazine propellant formulations, respectively.

\section{Conflict of Interests}

The authors declare that there is no conflict of interests regarding the publication of this paper.

\section{Acknowledgment}

The authors would like to thank the New Mexico Space Grant Consortium (NMSGC) for their financial support for this project. 


\section{References}

[1] V. Zakirov, M. Sweeting, T. Lawrence, and J. Sellers, "Nitrous oxide as a rocket propellant," Acta Astronautica, vol. 48, no. 512, pp. 353-362, 2001.

[2] S. A. Whitmore and S. N. Chandler, "Engineering model for self-pressurizing saturated- $\mathrm{N}_{2} \mathrm{O}$-propellant feed systems," Journal of Propulsion and Power, vol. 26, no. 4, pp. 706-714, 2010.

[3] J. R. Wallbank, P. A. Sermon, A. M. Baker, L. Courtney, and R. M. Sambrook, "Nitrous oxide as a green monopropellant for small satellites," in Proceedings of the 2nd International Conference on Green Propellants for Space Propulsion (ESA SP557 '04), A. Wilson, Ed., pp. 125-130, Sardinia, Italy, June 2004.

[4] V. Zakirov and H. Zhang, "A model for the operation of nitrous oxide monopropellant," Aerospace Science and Technology, vol. 12, no. 4, pp. 318-323, 2008.

[5] J. S. Tyll and R. Herdy, "The nitrous oxide-propane rocket engine: a final report for BAA 99-22. Allied Aerospace Industries/DARPA. GASL," Tech. Rep. 387, 2001.

[6] M. S. Balasubramanyam, M. Moser, and D. J. Sharp, "Catalytic ignition of nitrous oxide with propane/propylene mixtures for rocket motors ," in Proceedings of the 41st AIAA/ASME/SAE/ASEE Joint Propulsion Conference, pp. 1-8, AIAA, 2005.

[7] D. R. Lide, CRC Handbook of Chemistry and Physics, CRC Press, Boca Raton, Fla, USA, 89th edition, 2008.

[8] D. L. Keese, W. R. Escapule, M. C. Grubelich, and J. A. Ruffner, "Hydrogen peroxide-based propulsion and power systems," SAND Report 2004-1327, 2004.

[9] T. W. Ryan, S. T. Schwab, and H. H. Harlowe, "Ignition delays, heats of combustion, and reaction rates of aluminum alkyl derivatives used as ignition and combustion enhancers for supersonic combustion," NASA Contractor Report NAS1-18191, 1992, NAS 1.26:189581, http://ntrs.nasa.gov/ search.jsp?R=19940028362.

[10] H. G. Weiss, B. Johnson, H. D. Fisher, and M. Gerstein, "Modification of the hydrazine-nitrogen tetroxide ignition delay," AIAA Journal, vol. 2, no. 12, pp. 2222-2223, 1964.

[11] J. Marsel and L. Kramer, "Spontaneous ignition properties of metal alkyls," Symposium (International) on Combustion, vol. 7, no. 1, pp. 906-912, 1959.

[12] Metal Alkyls and Their Solutions, OMS 96.172.05, AkzoNobel, Chicago, Ill, USA, 2008.

[13] D. B. Malpass, "Appendix A: Pyrophoricity of metal alkyls," in Handbook of Transition Metal Polymerization Catalysts, R. Hoff and R. T. Mathers, Eds., pp. 551-562, Wiley, Hoboken, NJ, USA, 2010.

[14] S. Gordon and B. McBride, "Computer program for calculation of complex chemical equilibrium compositions and applications," NASA RP 1311, 1994, http://www.grc.nasa.gov/WWW/ CEAWeb/ceaWhat.htm.

[15] S. R. Jain, K. C. Adiga, and V. R. P. Verneker, "A new approach to thermochemical calculations of condensed fuel-oxidizer mixtures," Combustion and Flame, vol. 40, pp. 71-79, 1981.

[16] J. P. Leal and J. M. Simðes, "Standard enthalpy of formation of triethylaluminum," Organometallics, vol. 12, no. 4, pp. 14421444, 1993.

[17] L. Medard, Gas Encyclopaedia, Air Liquide, Elsevier Science Publishing, 1976, http://encyclopedia.airliquide.com/encyclopedia.asp. 

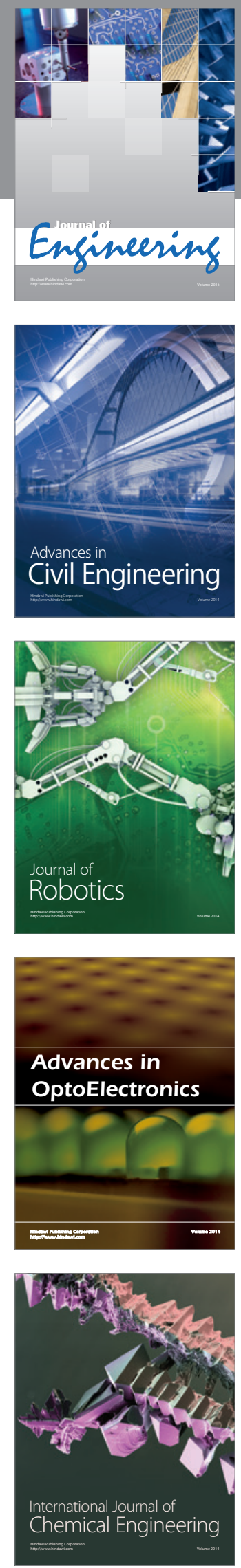

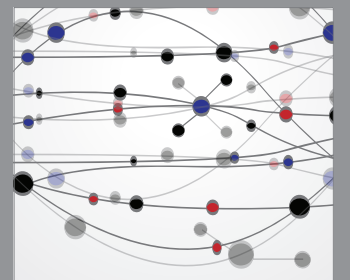

The Scientific World Journal
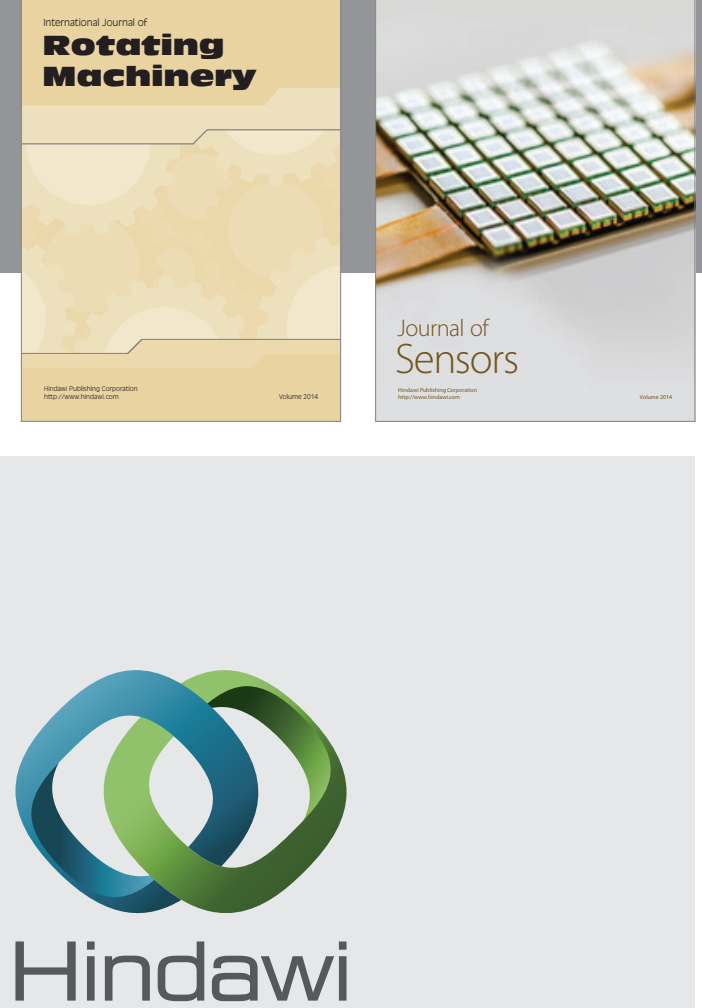

Submit your manuscripts at http://www.hindawi.com
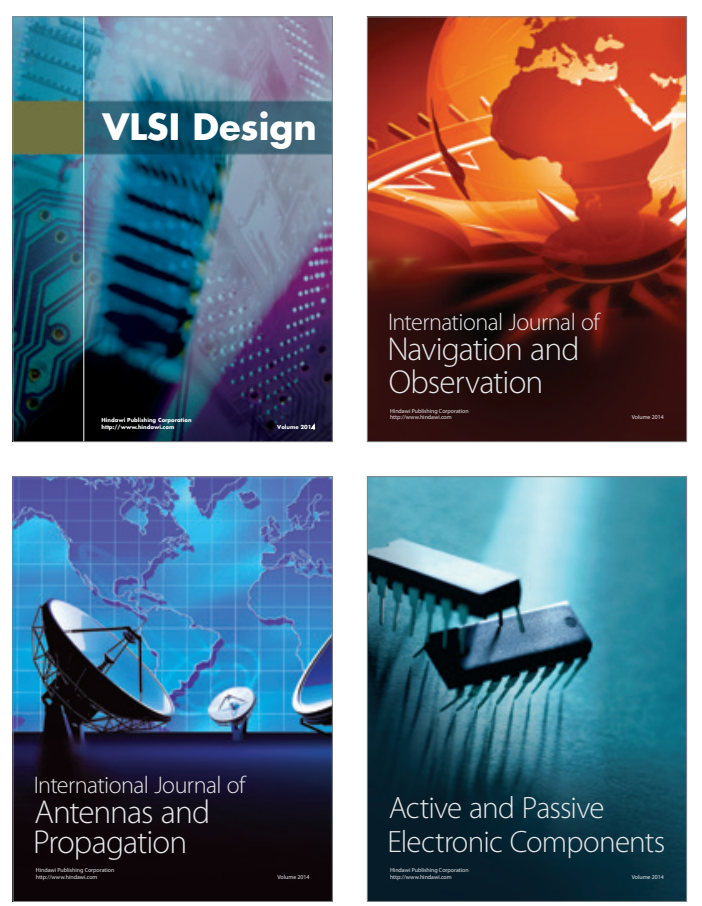
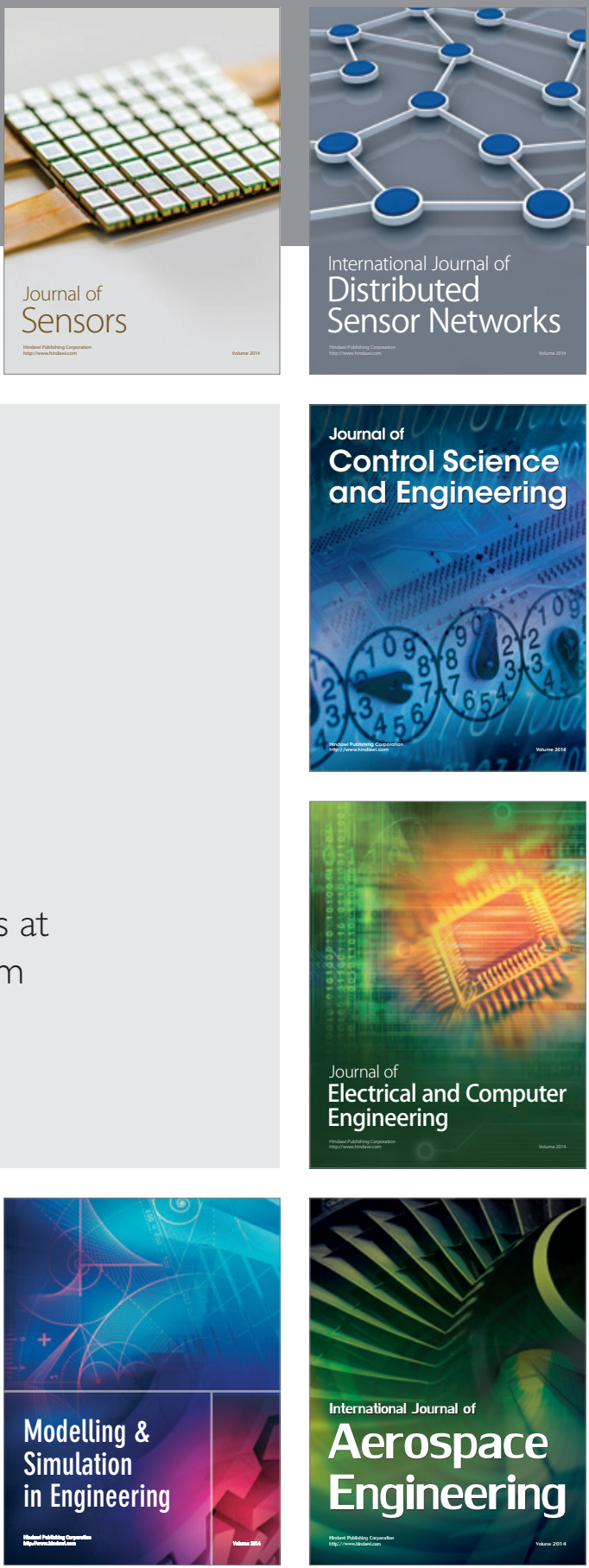

Journal of

Control Science

and Engineering
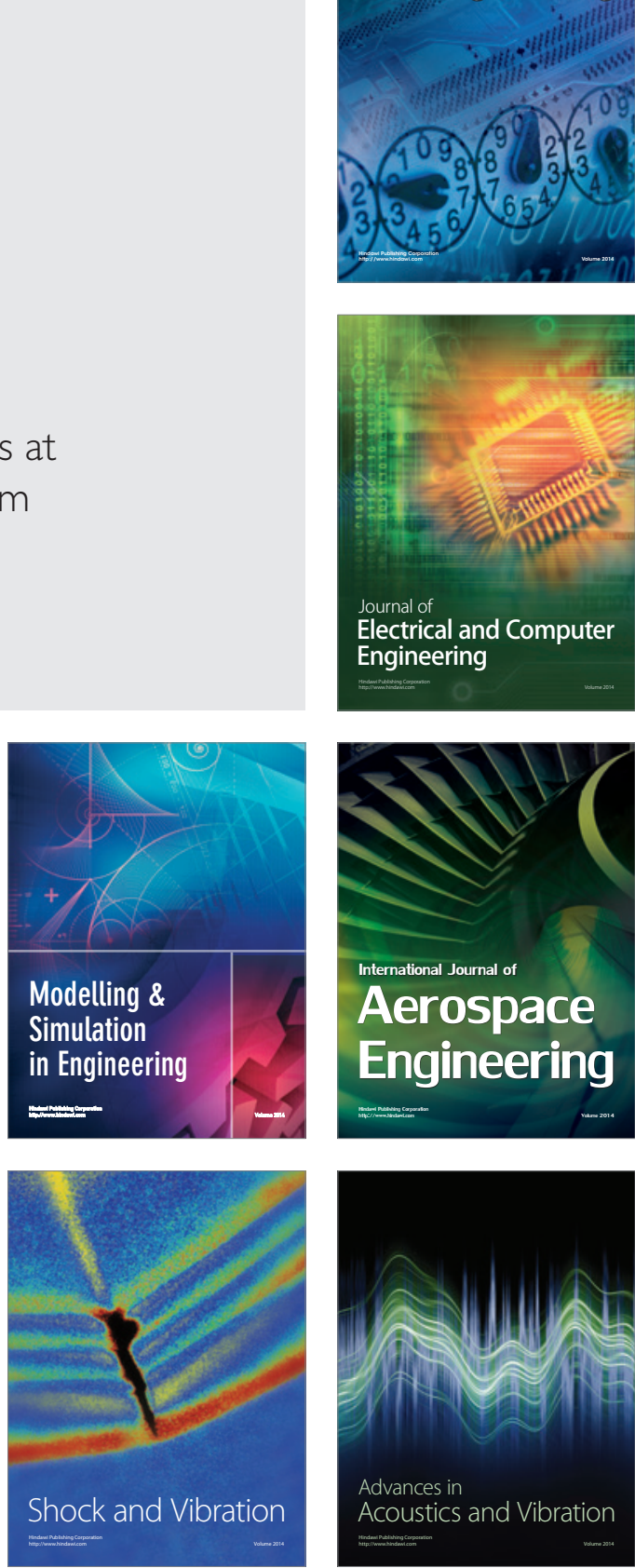